- Thaís Cristina Tebaldi

- Mara Helena Corso Pereira

- Magda Aparecida dos Santos Silva

- Mariana Junqueira Suyama

\section{Neurólise do plexo celíaco em criança com arterite de Takayasu}

\author{
Instituto do Coração do Hospital das Clínicas, Faculdade de Medicina \\ da Universidade de São Paulo, São Paulo
}

INTRロDUÇÃ̃

A arterite de Takayasu (AT) é uma doença inflamatória crônica que acomete a aorta, seus ramos e as artérias pulmonares. Pode provocar necrose asséptica da parede do vaso e, na fase tardia, o infiltrado inflamatório tende a ser substituído por fibrose, predispondo à trombose. O quadro clínico varia com a localização, a intensidade e a velocidade com que a doença se desenvolve. Na criança, a AT é a terceira vasculite mais comum, sendo a proporção entre os sexos de 2:1 (feminino/masculino); cerca de $1 / 3$ dos casos tem início antes dos 20 anos. A mortalidade em 5 anos chega a 35\%, sendo as causas: insuficiência cardíaca e renal, infartos, acidente vascular cerebral e ruptura de aneurisma. A melhor evolução associa-se ao diagnóstico precoce e à internação para tratamento clínico e cirúrgico das reagudizações e das crises álgicas.

RELATI DO CASD

Paciente masculino, 14 anos, com AT (diagnosticada há 4 anos após quadro clínico de vômitos, polidipsia, poliúria, perda de peso e crise hipertensiva), submetido à angioplastia com stent para correção de estenose da artéria renal esquerda. Apresentou isquemia mesentérica, necessitando de enterectomia e extensa ressecção de alças. Evoluiu com síndrome do intestino curto, dor abdominal intensa, desnutrição grave e duodenite, complicações que motivaram várias internaçôes, nas quais foi acompanhado pelo Grupo de Controle da Dor. Foi mantido ora com PCA venosa em bolus, ora com analgesia peridural contínua mais bolus, associação de drogas adjuvantes e de resgate. Evoluiu sem controle álgico adequado, além de apresentar parestesia, bloqueio motor e sedação; com prognóstico reservado, e sem alternativas de tratamento, optou-se por neurólise do plexo celíaco. Houve melhora da dor, recebendo alta com analgésico leve.

DISCUSรÃ

Efeitos colaterais como bloqueio motor, parestesias, sedação e vômitos tornaram os outros métodos de analgesia inviáveis. Dor muito intensa e melhora na qualidade de vida de pacientes com enfermidades de prognóstico reservado justificam o bloqueio neurolítico do plexo celíaco. A conduta foi eficaz no intuito de oferecer analgesia e alta hospitalar com qualidade de vida, considerando a limitação que a dor impunha ao paciente.

REFERÊNCIAS

1. Miller ML, et al. Vasculitis syndromes: Takayasu arteritis. In: Nelson Textbook of Pediatrics, 16th ed. WB Saunder. 2000;167:729-30.

2. Teixeira JM, et al. Procedimentos anestésicos e o tratamento da dor. In: Dor: epidemiologia, fisiopatologia, avaliação, síndromes dolorosas e tratamento. São Paulo: Grupo Editorial Moreira Jr. 2001;16:160-8.

Endereço para correspondência:

Thaís Cristina Tebaldi

Tel. (+55 11) 3069-6000 / 8224-8139

E-mail: ttebaldi@yahoo.com.br 